Elsevier Editorial System(tm) for Personality and Individual Differences Manuscript Draft

Manuscript Number: PAID-D-14-01000R2

Title: MORAL DISENGAGEMENT, THE DARK TRIAD, AND UNETHICAL CONSUMER ATTITUDES.

Article Type: Research Paper ( $<5000$ words)

Section/Category: Regular Issue

Keywords: dark triad; personality; psychopathy; moral disengagement; narcissism; Machiavellianism; unethical consumer attitudes; white-collar crime.

Corresponding Author: Prof. Vincent Egan, PhD, D. Clin Psy

Corresponding Author's Institution: University of Nottingham

First Author: Vincent Egan, PhD, D. Clin Psy

Order of Authors: Vincent Egan, PhD, D. Clin Psy; Natalie Hughes, MSc; Emma Palmer, PhD

Abstract: Purpose. Bandura's theory of moral disengagement explains how otherwise ethical persons can behave immorally. We examined whether a trait model of general personality and the "dark triad" underlay moral disengagement, the relationship these constructs have to unethical consumer attitudes, and whether moral disengagement provided incremental validity in the prediction of antisocial behaviour. Methods. Self-report data were obtained from a community sample of 380 adults via an online survey that administered all measures. Results. Correlations between unethical consumer attitudes, lower Agreeableness, lower Conscientiousness, higher moral disengagement, higher psychopathy, and higher Machiavellianism were captured by a single factor. When this broad factor was examined using regression, demographic, personality and the dark triad traits all predicted moral disengagement, specific influences being age, education, Intellect, psychopathy, and Machiavellianism. A similar model examining predictors of unethical consumer attitudes again found all blocks contributed to the outcome, with specific influence provided by age, Intellect, and moral disengagement, the latter showing incremental validity as a predictor of unethical consumer attitudes.Conclusions. Moral disengagement is based on low Agreeableness, Machiavellianism and psychopathic-type traits, but provides incremental validity in predicting antisocial attitudes to a trait model alone. Narcissism is neither related to moral disengagement, nor unethical consumer attitudes. 
Moral Disengagement, the dark triad, and unethical consumer attitudes.

$$
\text { Vincent Egan }{ }^{1 *} \text { Natalie Hughes }{ }^{2} \text {, and Emma J. Palmer }{ }^{2}
$$

1. Centre for Family and Forensic Psychology, YANG Fujia Building, University of Nottingham, Wollaton Road, Nottingham, NG8 1BB, UK. (Email: vincent.egan@nottingham.ac.uk; Internet: http://www.nottingham.ac.uk/medicine/about/psychiatryandappliedpsychology/people/vincent.egan )

${ }^{2}$. School of Psychology, University of Leicester, Henry Wellcome Building, Lancaster Road, Leicester, LE1 9HN, UK (email: nathughes@ hotmail.co.uk, ejp8@le.ac.uk)

*Corresponding author

For: Personality and Individual Differences

Running header: Moral disengagement and the dark triad

Date: Monday, 17 November 2014 
Highlights of MORAL DISENGAGEMENT, THE DARK TRIAD AND UNETHICAL CONSUMER ATTITUDES

- Moral disengagement explains how ostensibly good people can do very bad things.

- Agreeableness's influence on moral disengagement is reduced by the introduction of DT traits.

- Moral disengagement is predicted by younger age, lower Intellect, psychopathy and Machiavellianism.

- Unethical consumer attitudes are specifically predicted by younger age, lower Intellect, and greater moral disengagement.

- Moral disengagement provides incremental validity to a model using trait measures alone. 


\section{MORAL DISENGAGEMENT, THE DARK TRIAD, AND UNETHICAL CONSUMER}

\section{ATTITUDES.}

While people generally know right from wrong, some find it easier to disengage from their ethical principles than others. This behaviour is called moral disengagement. A common example of moral disengagement is consumer dishonesty, which is defined as: "the moral principles and standards that guide behavior of individuals or groups as they obtain, use, and dispose of goods and services" (Muncy \& Vitell, 1992, pp. 298). Apparent petty dishonesty (Egan \& Taylor, 2010) harms UK businesses to the cost of at least £294 million pounds per annum (National Fraud Authority, 2011). The current study examined general and darker personality traits underpinning moral disengagement, using unethical consumer attitudes as a specific criminological outcome.

Moral disengagement (Bandura, 1986) provides a specific model to explain how persons breach their personal ethics. Individuals generally seek consistency in held moral beliefs to avoid a discrepancy between what they believe to be right, and how they actually behave. This is because conflicts between inconsistent behaviours and beliefs classically produce feelings of psychological discomfort known as cognitive dissonance (Festinger, 1957). If one can disengage from personal moral standards, it becomes easier to justify engaging in behaviours normally considered immoral. Bandura, Barbaranelli, Caprara and Pastorelli (1996) described eight mechanisms by which disengagement of morals may occur; moral justification (justifying a wrongful act as virtuous in terms of the perceived potential outcome); euphemistic labelling (using language to conceal guilt by distorting what happened, as when a thief says they "found" a stolen item); advantageous comparison (justifying a wrongful act by fallaciously comparing it to another's more egregious acts); displacement of responsibility (when an individual's wrong-doing is attributed to being under pressure or orders from another); diffusion of responsibility (where a shared decision to 
behave immorally means no individual involved in the wrongful act believes they are fully culpable for the events which occur); disregarding or distorting the consequences (ignoring or minimising the outcome of the wrongful action); dehumanisation (rejecting the human qualities of one's opponent and seeing them as bestial); and attribution of blame (suggesting the blame for wrongful action lies in the provocation of the victim who brought the trouble on themselves). Such moral disengagement is seen in rationalisations for antisocial and delinquent acts (Shulman, Cauffman, Piquero \& Fagan, 2011; Bandura, Caprara, Barbaranelli, Pastorelli \& Regalia, 2001).

Moral disengagement is significantly and positively correlated with unethical workplace decision making and behaviour, and is an indirect proxy for risk of white-collar offending (Christian \& Ellis, 2013; Barsky, 2011). For example, Detert, Treviño, and Sweitzer, (2008) found higher-order qualities of personality such as empathy and moral identity (the degree moral concerns are perceived as part of your own identity; Aquino \& Reed, 2002) correlated negatively with an individual's propensity to morally disengage, whereas general cynicism and chance locus of control orientation (the belief that chance determines an individual's outcome) were positively correlated with the construct. They also found the relationship between higher-order personality and unethical decision making mediated by moral disengagement. Moore, Detert, Treviño, Baker and Mayer (2012) subsequently found positive significant associations between moral disengagement, selfreported unethical behaviour, and self-reported decisions to commit fraud. While these results are salutary, few studies have examined more fundamental influences underpinning moral disengagement or it's correlates, for example, the Five-Factor / Big Five Models of personality (FFM/BFM; McCrae \& John, 1992; Goldberg, 1999), or the negative dispositional traits found within the Dark Triad (Paulhus \& Williams, 2002) 
The Dark Triad (DT) comprises three constructs; psychopathy, narcissism, and Machiavellianism. Though scores on the DT correlate with traits derived from both FFM and BFM conceptualisations of general personality (Jakobwitz \& Egan, 2006; Pailing, Boon \& Egan, 2014), Agreeableness has the greatest relative importance for DT prediction (O'Boyle, Donelson, Banks, Story, \& White, in press). Exemplifying O'Boyle et al's observations, Egan, Chan, and Shorter (2014) found Machiavellianism and psychopathy driven by low Agreeableness alone, whereas narcissism presented a much more complex FFM profile. This finding reiterated narcissism as the 'lightest' dimension of the DT (Furnham, Richards, \& Paulhus, 2013). When measured concurrently with narcissism, psychopathy and Machiavellianism are better predictors of unethical and antisocial outcomes (Tang, Chen \& Sutarso, 2008; Kish-Gephart, Harrison \& Treviño, 2010). O’Boyle et al (in press) argue that given Machiavellianism and psychopathy are highly correlated, and show a similar pattern of correlations in relation to the FFM, these two constructs may be better regarded as a single psychopathic entity, albeit one differentially expressed. This view has a precedent in the work of McHoskey, Worzel, and Szyarto (1998).

There have been a number of specific studies using models from social psychology examining aspects of moral disengagement. Neutralisation, false-returning purchased items as "faulty" or "unwanted" (associated with thrill- seeking and less self-consciousness), anticipated guilt following unethical consumer activity, and the influence of guilt and opportunism on receiving too much change at a supermarket checkout have all been examined (De Bock \& Van Kenhove, 2011; Harris, 2008;Steenhaut \& Van Kenhove, 2006; Steenhaut \& Van Kenhove, 2005). Moore et al's (2012) systematic studies into moral disengagement in occupational settings measured Machiavellianism alongside measures of empathy and perspective-taking, finding these predictors associated with a greater ability to morally disengage, their effect was replicated across two studies, while a fourth study found 
dispositional guilt negatively correlated with the propensity to morally disengage. All of these studies touch on aspects of the relationship between general personality, moral disengagement, the Dark Triad, and unethical consumer activity, but none studied the dispositional foundations upon which their findings arguably stand.

Bandura (1986) suggested the cognitive pathways by which moral disengagement shapes antisocial behaviour are similar to those generally rationalising interpersonal aggression and delinquent conduct. The current study explores the relationship between general personality, moral disengagement, the Dark Triad, and unethical consumer behaviour, examining two questions. Firstly, how much is moral disengagement driven by more basic dispositional traits, in particular low Agreeableness, low Conscientiousness, and the dark triad. Secondly, does the addition of moral disengagement provide incremental validity to a basic trait model predicting unethical consumer attitudes in which low Agreeableness, low Conscientiousness and the DT are expected to explain most of the variance?

\section{METHOD}

\section{Sample and Procedure}

This study used a within-subjects correlational design, and was approved by the research ethics committee. G-Power (Faul, Erdfelder, Lang, \& Buchner, 2007) suggesting 108 persons were needed for a medium effect size at a statistical power level of 0.8 when using a .05 criterion for statistical significance of $\mathrm{P}<.05$. The study was administered on-line via GoogleDocs and 382 persons participated. Having oversampled, neither type 1 nor type 2 errors were a concern, and our effect size became more important. To focus on the most important effects, we adopted a significance criterion of $\mathrm{P}<.01$ or above.

A convenience participants sample were recruited through social media, the internal email of several businesses, word of mouth, and a university student participation resource in 
exchange for course credits. All persons gave informed consent. Two participants were identified as outliers on the psychopathy and general personality measures, and were excluded from the data set, giving a final sample of 380 participants (271 females, 109 males). Over half the final sample (51.90\%) was employed (41.1\% full-time, $10.8 \%$ parttime). Under a third of the cohort were students (28.2\%), $11.3 \%$ were retired, and $1.8 \%$ unemployed. The mean age was 37.99 years $(S D=16.50$, range $18-83$, median age $=34)$.

\section{Measures}

In all cases, scales used Likert responding, with items ranged from 1 (strongly disagree) to 5 ("strongly agree"), 3 being a neutral response. Some items in the scales were reverse-keyed; items were corrected as necessary before analyses.

1. The International Personality Item Pool (IPIP-50: Goldberg, 1999). The IPIP is a 50-item measure of the "Big Five" personality dimensions; extraversion, agreeableness, conscientiousness, emotional stability and intellect. Each of the five scales was measured using 10 items, with a mean reliability of 0.84 for the five scales (Goldberg, 1999). Greater scores indicated higher levels of the dimension measured.

2. The Muncy-Vitell Consumer Ethics Scale (CES: Vittell \& Muncy, 2005). The CES is a 31item measure with seven subscales, all of which are reliable and valid. Four of the subscales relate to unethical consumer attitudes; actively benefiting from illegal actions (ACT; 5 items), passively benefiting (PAS; 6 items), questionable but legal actions (QUEST; 5 items) and media downloading (DL; 2 items). (The other three CES subscales relate to positive ethical behaviours; recycling ( 4 items), behaving in an honest way (4 items), and activities perceived as involving no harm (e.g., recording a programme off the TV rather than buying the DVD; 5 items)). For the purpose of this study, greater unethical consumer behaviour was defined by higher scores on the sum of three of the subscales; ACT, PAS and QUEST, which provided 
an overall index of general unethical consumer behaviour, and avoided age effects associated with younger persons illegally downloading media from the Internet.

3. The Short DT (SD3: Jones \& Paulhus, 2014). The SD3 is a 27-item measure to briefly measure the three DT traits of psychopathy, Machiavellianism and narcissism. High scores on these scales indicate higher levels of the trait the scale is measuring. Alpha reliabilities for SD3 psychopathy, narcissism and Machiavellianism subscales are $.80, .77$ and .73 respectively (Paulhus \& Jones, 2014).

4. The Moral disengagement scale (Detert et al., 2008). The moral disengagement scale is a 24-item measure based on Bandura et al.’s (1996) measure of moral disengagement for children, with wording modified to apply to an adult sample. (For example, the statement 'If kids fight and misbehave in school it is their teacher's fault' on Bandura's scale was changed to 'People are not at fault for misbehaving at work if their managers mistreat them'); another example item was "Some people deserve to be treated like animals". Higher scores on this measure indicate higher levels of moral disengagement. This scale has a documented overall alpha coefficient of .87. We analysed the scale using Detert et al's conceptualised subscales, but found the individual items did not load on their factors as claimed, and the specific subscales were unreliable. However, the overall reliability of the scale was 0.84 , so we used the total score of the measure to assess general moral disengagement.

\section{Plan of analysis.}

All scales were tested for reliability, skewness and kurtosis. External validity was tested by exploring univariate correlations with associated constructs, All measures yielded reliability statistics $>.7$ or marginally below. Normality tests tested whether the distribution of data was suitable for parametric statistics. Kolmogorov-Smirnov analyses indicated our data were not normally distributed. As square-root and $\log 10$ transformations of the data did not improve the skew and kurtosis, data were analysed using non-parametric methods. 


\section{RESULTS}

---Insert table 1 here ----

Table 1 shows the mean, standard deviation and reliability statistics for the measures used within this study, along with their (non-parametric) intercorrelation; only associations significant at $\mathrm{P}<.001$ were reported (table 1). Results show significant correlations between unethical consumer attitudes and lower Agreeableness, lower Conscientiousness, higher moral disengagement, higher psychopathy, and higher Machiavellianism. Scores on moral disengagement significantly correlated with lower Agreeableness, lower Conscientiousness, all three DT components, and unethical consumer attitudes.

---Insert table 2 here ----

\section{Dimensionality of the data}

To identify dimensional influences within the data set, the non-parametric correlations matrix was subject to a PCA with oblique rotation to differentiate the variance (Ritter, 2012). Extracting spurious factors was avoided by using parallel analysis to estimate a minimal eigenvalue for factor extraction (O'Connor, 2000); the Monte Carlo calculation based on 10 variables and 380 participants indicated factors with an eigenvalue above 1.27 should be extracted. The Kaiser-Meyer-Olkin measure of sampling adequacy was 0.66, Bartlett's test of sphericity $\chi 2(45)=840.145, \mathrm{p}<0.001$, suggesting correlations between variables were large enough for PCA to be used appropriately. Table 2 presents the pattern matrix of a two factor solution, which explained $45.2 \%$ of total variance. Using a criterion of 0.4 or above to identify significant loadings within each factor, the first factor clearly captured all the antisocial variance, with high loadings for psychopathy, total moral disengagement, Machiavellianism, Agreeableness, Unethical consumer attitudes, Conscientiousness, and, 
lowest-loading in this factor, Narcissism. Narcissism had a split loading, as it had the highest loading for the second factor, which also comprised extroversion and intellect, reiterating the finding that there is considerable non-pathological variance in general narcissism once it's antisocial elements have been removed.

--- Insert table 3 here ---

\section{$\underline{\text { Regression analyses. }}$}

To untangle the predictive and possibly incremental influences on moral disengagement and unethical consumer attitudes, two stepwise regressions were calculated, the raw data being ranked to overcome problems with skew. The first sought to predict moral disengagement from three blocks; demographics (age, education, and education), general personality (Extroversion, Emotional Stability, Agreeableness, Conscientiousness and Intellect); and the DT (psychopathy, Machiavellianism, and narcissism). The second regression used a similar model and blocks, but the predictor outcome was unethical consumer attitudes, and added a single variable fourth block into the stepwise regression - total moral disengagement (table 3). A third of the total moral disengagement variance was predicted by the three blocks; the introduction of the DT led Agreeableness to drop out of the model, it previously having significantly predicted the outcome (standardised beta $=-0.23, \mathrm{P}<.001$, reducing to -0.01 in block 3). This suggests that all the Agreeableness variance was taken up by DT predictors.

The same structure was used to analyse unethical consumer attitudes. All four blocks contributed to the outcome, explaining $28 \%$ of the variance. The introduction of moral disengagement to the model significantly increased the amount of variance predicted, showing that moral disengagement has incremental validity in predicting a criminological outcome, over and above general personality traits and the dark triad. Lastly, the introduction of moral disengagement led the predictive value of Conscientiousness and Machiavellianism 
(predictors before -moral disengagement was introduced) to drop out of the model, suggesting these underlay moral disagreement.

\section{DISCUSSION}

The current study investigated the relationships between general personality traits, the DT, moral disengagement, and unethical consumer attitudes. Significant separate correlations between unethical consumer attitudes, lower Agreeableness, lower Conscientiousness, higher moral disengagement, higher psychopathy, and higher Machiavellianism were captured by a single factor capturing all of the more unpleasant variance in the data set. When this broad factor was examined using regression methods, demographic, personality and DT blocks all predicted moral disengagement, but more specific influences were age, education, Intellect, psychopathy, and Machiavellianism, with the DT traits forcing Agreeableness out of the model, perhaps due to their taking almost all of the Agreeableness variance. A similar model examining predictors of unethical consumer attitudes again found all blocks contributed to the outcome, with specific influence provided by age, Intellect, and moral disengagement, the latter showing incremental validity as a predictor of unethical consumer attitudes. Moral disengagement's entrance into the model led Conscientiousness and Machiavellianism to lose significant influence, possibly because they partly underlie moral disengagement in the first place. These results suggest that while moral disengagement is associated with a variety of darker personality traits, it also captures aspects of unpleasant character not assessed by other measures. Our results suggest assessments of criminal cognition augment dispositional measures of darker personality to predict antisocial attitudes.

We did not find narcissism predicted either moral disengagement or unethical consumer attitudes. The factor analysis appeared to split narcissism into a two sources of 
variance; antisocial and unpleasant aspects of the construct, and a more benign form associated with simply being extroverted and confident about their competencies. Narcissism is not always an indicator of pathology and risk, and may even be adaptive (Ackerman, Witt, Donnellan, Trzesniewski, Robins, \& Kashy, 2011). Meta-analysis of narcissism and counterproductive work behaviour supports this view; while the narcissistic facet of Entitlement/ Exploitativeness relates positively to antisocial behaviour at work, the Leadership/Authority facet of narcissism is negatively correlated with malign workplace activity (Grijalva \& Newman, 2014).

Unethical attitudes overlap with criminal behaviours (Kish-Gephert et al., 2010). Understanding the mechanisms whereby these individuals engage in these behaviours can further limit harm. For example, organisational implementation of widely publicised (and enforced) policies regarding personal responsibility for actions may inhibit some individuals from so easily disengaging from principled behaviour. Moreover, if organisations are knowledgeable about individuals more likely to morally disengage and hold unethical attitudes, resources and training can be directed toward improving or monitoring the decision-making processes that these individuals engage in, implementing structures of governance to inhibit such activity (Flegel, Vayssière, \& Bitz, 2010).

Some individuals in the workplace may fail to take full responsibility for their actions and act in a conscienceless way (Boddy, 2006; Wu \& Lebreton, 2011). In contexts where differential advantage follows from audacious or cynical practice, it is understandable why aspects of the DT may be valued in some modern workplaces, and why, despite the potential corporate losses individuals high in on facets of the DT could cause, DT qualities may be potentially expedient for an employer (Mullins-Sweatt, Glover, Derefinko, Miller, \& Widiger, 2010; Smith \& Lilienfeld, 2013). Meta-analysis by O’Boyle Forsyth, Banks, and McDaniel (2012) observed that the DT - in particular psychopathy and Machiavellianism - 
explained variance associated with counter-productivity at work, but not overall job performance. We also found Machiavellianism and psychopathy significant independent predictors of moral disengagement.

The current study had a number of limitations. Generalisation of findings to the workplace can only be made on the assumption unethical consumer attitudes mediate workplace and private behaviour. Prior research suggests this is the case (e.g., Christian \& Ellis, 2013). A stronger concern is that we lacked an objective antisocial behavioural outcome; replication in a workplace with an occupational criterion may overcome this limitation. Our data were skewed, and as the sample was opportunistic, we were unable to recruit a more homogenous cohort; future such studies could use quota sampling or the targeting of specific populations to reduce variation. However, our sample may reflect the heterogeneity of the community more accurately than narrower samples could reveal. Another criticism is that with no benefit or consequence to participants expressing unethical attitudes in our study, the methodology could encourage participants to exaggerate unethical attitudes; however, the pointlessness of dissimulation could equally inhibit unethical choices, as socially desirable responding serves no useful function in an anonymous study. Metaanalyses suggest problems with social desirability effects are often exaggerated relative to the evidence (Richman, Kiesler, Weisband, \& Drasgow, 1999; Ones, Viswesvaran, \& Reiss, 1996). Our survey followed an optimal scale administration strategy to reduce putative social desirability effects, which reduces to ensuring privacy and anonymity for respondents.

Our results reiterate that there is more to moral disengagement than personality disposition, and that malign cognitions also contribute to antisocial and antagonistic behaviour (Egan, McMurran, Richardson, \& Blair, 2000). While White-Ajmani and Bursik (2013) found moral disengagement specifically related to a deviant outcome (aggression) in revenge situations (suggesting situational factors are relevant to understanding an individual's 
propensity to morally disengage), our hypothetical unethical consumer attitudes outcome was anodyne and abstract; however, it still generated a strong effect. Nevertheless, we support replication of our study with more behavioural and ecologically-valid outcome measures of dishonesty than a self-report scale. Finally, we did not report scores from the moral disengagement measure using the specific subscales ostensibly in the measure. This is because our preliminary item- and reliability-analyses did not reveal the same structure as that found by Detert et al (2008). However, we found the scale's total score very satisfactory.

Our findings indicate that moral disengagement is a useful adjunct to more commonly used trait measures of dark personality, and that narcissism had little specific influence on such outcomes once concurrent antisocial traits were taken into consideration. Unethical consumer attitudes are a useful criminological outcome as they test values and behaviours in otherwise non-offending persons, as the behaviour is itself not without significant social implications. While it may be the case that particular components of moral disengagement are more salient than others, we found reliability for the overall measure greater than for the subscales, suggesting that further work is required to create a suitable metric that can differentiate facets of the construct. 


\section{REFERENCES}

Ackerman, R. A., Witt, E. A., Donnellan, M. B., Trzesniewski, K. H., Robins, R. W., \& Kashy, D. A. (2011). What does the Narcissistic Personality Inventory really measure? Assessment, 18 (1), 67-87. Doi: 10.1177/1073191110382845

Aquino, K., \& Reed II, A. (2002). The self-importance of moral identity. Journal of personality and social psychology, 83(6), 1423-1440. DOI: http://dx.doi.org/10.1037/0022-3514.83.6.1423.

Bandura, A. (1986). Social foundations of thought and action: A social cognitive theory. Englewood Cliffs, NJ US: Prentice-Hall, Inc.

Bandura, A., Barbaranelli, C., Caprara, G. V., \& Pastorelli, C. (1996). Mechanisms of moral disengagement in the exercise of moral agency. Journal of Personality and Social Psychology, 71(2), 364-374. doi:10.1037/0022-3514.71.2.364

Bandura, A., Caprara, G. V., Barbaranelli, C., Pastorelli, C., \& Regalia, C. (2001). Sociocognitive self-regulatory mechanisms governing transgressive behavior. Journal of Personality and Social Psychology, 80, 125- 135. doi:10.1037/0022-3514.80.1.125

Barsky, A. (2011). Investigating the effects of moral disengagement and participation on unethical work behavior. Journal of Business Ethics, 104(1), 59-75. doi:10.1007/s10551-011-0889-7

Boddy, C. (2006). The dark side of management decisions: Organisational psychopaths. Management Decision, 44(10), 1461-1475. doi:10.1108/00251740610715759

Christian, J., \& Ellis, A. J. (2013). The crucial role of turnover intentions in transforming moral disengagement into deviant behavior at work. Journal Of Business Ethics, doi:10.1007/s10551-013-1631-4. 
De Bock, T., \& Van Kenhove, P. (2011). Double standards: the role of techniques of neutralization. Journal of Business Ethics, 99 (2), 283-296. DOI: 10.1007/s10551010-0654-3.

Detert, J. R., Treviño, L. K., \& Sweitzer, V. L. (2008). Moral disengagement in ethical decision making: A study of antecedents and outcomes. Journal of Applied Psychology, 93(2), 374-391. doi:10.1037/0021-9010.93.2.374

Egan, V., Chan, S., \& Shorter, G. (2014). The Dark Triad, happiness and subjective wellbeing. Personality and Individual Differences, 67 (9), 17-22. doi: http://dx.doi.org/10.1016/j.paid.2014.01.004

Egan, V., McMurran, M., Richardson, C., \& Blair, M. (2000). Criminal cognitions and personality: what does the PICTS really measure? Criminal Behaviour and Mental Health, 10 (3), 170 - 184. doi:10.1002/cbm.355.

Egan, V., \& Taylor, D. (2010). Shoplifting, unethical consumer behaviour, and personality. Personality and Individual Differences, 48 (8), 878-883. doi: 10.1016/j.paid.2010.02.014

Faul, F., Erdfelder, E., Lang, A.-G., \& Buchner, A. (2007). G*Power 3: A flexible statistical power analysis program for the social, behavioral, and biomedical sciences. Behavior Research Methods, 39 (2), 175-191. doi: 10.3758/BF03193146.

Festinger, L. (1957). A theory of cognitive dissonance. Stanford University Press.

Flegel, U., Vayssière, J., \& Bitz, G. (2010). A state of the art survey of fraud detection technology. In C.W. Probst, M. Bishop, D. Gollmann, J.A. Allen Hunke (Eds). Insider Threats in Cyber Security (pp. 73-84). New York, USA: Springer.

Furnham, A., Richards, S. C., \& Paulhus, D. L. (2013). The Dark Triad of personality: A 10 year review. Social and Personality Psychology Compass, 7(3), 199-216. doi: $10.1111 / \mathrm{spc} 3.12018$. 
Goldberg, L. R. (1999). A broad-bandwidth, public-domain, personality inventory measuring the lower-level facets of several five-factor models. In I. Mervielde, I. Deary, F. De Fruyt, \& F. Ostendorf (Eds.). Personality psychology in Europe (Vol. 7, pp. 7-28). Tilburg, The Netherlands: Tilburg University Press.

Grijalva, E., \& Newman, D. A. (2014), Narcissism and counterproductive work behavior (CWB): Meta-analysis and consideration of collectivist culture, big five personality, and narcissism's facet structure. Applied Psychology: An International Review. (in press). doi: 10.1111/apps.12025

Harris, L.C.F. (2008). Fraudulent return proclivity: An empirical analysis. Journal of Retailing, 84 (4), 461-476. DOI: 10.1016/j.jretai.2008.09.003

Jakobwitz, S., \& Egan, V. (2006). The Dark Triad and normal personality traits. Personality and Individual Differences, 40, 331-339. doi:10.1016/j.paid.2005.07.006.

Jones, D. N., \& Paulhus, D. L. (2014). Introducing the short Dark Triad (SD3): A brief measure of dark personality traits. Assessment, 21, (1), 28-41. Doi:10.1177/1073191113514105

Kish-Gephart, J., Harrison, D. A., \& Treviño, L. K. (2010). Bad apples, bad cases, and bad barrels: Meta-analytic evidence about sources of unethical decisions at work. Journal of Applied Psychology, 95(1), 1-31. doi:10.1037/a0017103

McCrae, R.R., \& John, O.P. (1992). An introduction to the five-factor model and its applications. Journal of Personality, 60 (2), 175-215. doi:10.1111/j.14676494.1992.tb00970.x

McHoskey, J. W., Worzel, W., \& Szyarto, C. (1998). Machiavellianism and psychopathy. Journal of Personality and Social Psychology, 74(1), 192 - 210. doi: 10.1037//00223514.74.1.192 
Moore, C., Detert, J. R., Treviño, L. K., Baker, V. L., \& Mayer, D. M. (2012). Why employees do bad things: Moral disengagement and unethical organizational behavior. Personnel Psychology, 65(1), 1-48. doi:10.1111/j.1744-6570.2011.01237.x

Mullins-Sweatt, S. N., Glover, N. G., Derefinko, K. J., Miller, J. D., \& Widiger, T. A. (2010). The search for the successful psychopath. Journal of Research in Personality, 44(4), 554-558. doi:10.1016/j.jrp.2010.05.010

Muncy, J.A., \& Vitell, S.J. (1992). Consumer ethics : an investigation of the ethical beliefs of the final consumer. Journal of Business Research, 24 (1), 297-311. Doi: 10.1007/BF00872270

National Fraud Authority. (2011). Annual Fraud Indicator. London, UK. (downloaded July 17th, 2014 from: https://www.gov.uk/government/uploads/system/uploads/attachment_data/file/118532 /annual-fraud-indicator-2011.pdf

O'Boyle, E. H. J., Forsyth, D. R., Banks, G. C., \& McDaniel, M. A. (2012). A meta-analysis of the Dark Triad and work behavior: A social exchange perspective. Journal of Applied Psychology, 97(3), 557-579. doi:10.1037/a0025679; 10.1037/a0025679.supp

O'Boyle, E.H., Donelson R.F., Banks, G.C., Story, P.A., \& White, C.D. (in press). A metaanalytic test of redundancy and relative importance of the Dark Triad and five factor model of personality. Journal of Personality. doi: 10.1111/jopy.12126

O'Connor, B.P. (2000), SPSS and SAS programs for determining the number of components using parallel analysis and Velicer's MAP test. Behavior Research Methods, Instruments and Computers, 32 (3), 396-402. doi: 10.3758/BF03200807.

Ones, D.S., Viswesvaran, C., \& Reiss, A.D. (1996). Role of social desirability in personality testing for personnel selection: The red herring. Journal of Applied Psychology, 81(6), 660-679. doi: 10.1037/0021-9010.81.6.660 
Pailing, A., Boon, J., \& Egan, V. (2014). Personality, the Dark Triad and violent behaviour. Personality and Individual Differences, 67 (1), 81 - 86. DOI: 10.1016/j.paid.2013.11.018.

Paulhus, D. L., \& Williams, K. M. (2002). The Dark Triad of personality: Narcissism, Machiavellianism and psychopathy. Journal of Research in Personality, 36(6), 556563. doi:10.1016/S0092-6566(02)00505-6

Richman, W.L., Kiesler, S., Weisband, S., \& Drasgow, F. (1999). A meta-analytic study of social desirability distortion in computer-administered questionnaires, traditional questionnaires, and interviews. Journal of Applied Psychology, 84(5), 754-775. doi: $10.1037 / 0021-9010.84 .5 .754$

Ritter, N. (2012). A comparison of distribution-free and non-distribution free methods in factor analysis. Paper presented at Southwestern Educational Research Association (SERA) Conference 2012, New Orleans, LA (ED529153). Downloaded from: http://www.academia.edu/1713092/A_Comparison_of_Distribution_Free_and_Nondistribution_Free_Factor_Analysis_Methods, June 2013.

Shulman, E. P., Cauffman, E., Piquero, A. R., \& Fagan, J. (2011). Moral disengagement among serious juvenile offenders: A longitudinal study of the relations between morally disengaged attitudes and offending. Developmental Psychology, 47(6), 16191632. doi:10.1037/a0025404

Smith, S., \& Lilienfeld, S. O. (2013). Psychopathy in the workplace: The knowns and unknowns. Aggression and Violent Behavior, 18(2), 204-218. doi:10.1016/j.avb.2012.11.007.

Steenhaut, S., \& Van Kenhove, P. (2005). Relationship commitment and ethical consumer behavior in a retail setting: The case of receiving too much change at the checkout. Journal of Business Ethics, 56 (4), 335-353. DOI: 10.1007/s10551-004-5969-5. 
Steenhaut, S., \& Van Kenhove, P. (2006). The mediating role of anticipated guilt in consumers' ethical decision-making. Journal of Business Ethics, 69 (3), 269-288. DOI: $10.1007 / \mathrm{s} 10551-006-9090-9$.

Tang, T. L., Chen, Y., \& Sutarso, T. (2008). Bad apples in bad (business) barrels: The love of money, Machiavellianism, risk tolerance, and unethical behavior. Management Decision, 46(2), 243-263. doi:10.1108/00251740810854140

Vitell, S. J., \& Muncy, J. (2005). The Muncy-Vitell consumer ethics scale: a modification and application. Journal of Business Ethics, 62(3), 267-275. doi:10.1007/s10551-0057058-9

White-Ajmani, M. L., \& Bursik, K. (2013). Situational context moderates the relationship between moral disengagement and aggression. Psychology Of Violence, doi: $10.1037 / \mathrm{a} 0031728$

Wu, J., \& Lebreton, J. M. (2011), Reconsidering the dispositional basis of counterproductive work behavior: the role of aberrant personality. Personnel Psychology, 64 (3), 593626. doi: 10.1111/j.1744-6570.2011.01220.x 
Table 1: Summary of means, SDs, and correlations (Spearman's rho) between measured variables, reliability of measure on leading diagonal in parentheses $(\mathrm{n}=380$ )

Extraversion Agreeableness Conscientiousness Emotional Stability Intellect Moral Machiavellianism Psychopathy Narcissism Unethical

Disengagement

Consumer

attitudes

$\begin{array}{cccc}\text { Extroversion } & (0.91) & .22 * * * & .07 \\ \text { Agreeableness } & & (0.81) & .30 * * * \\ & & & (0.82)\end{array}$

Emotional Stability

Intellect

Moral disengagement

Machiavellianism

Psychopathy

Narcissism

Unethical consumer attitudes

$\begin{array}{cc}.17 * * * & .17 * * * \\ .00 & .05 \\ .13 & .12 \\ (0.85) & -.14 \\ & (0.69) \\ & \\ & \end{array}$

-.11
$-.32 * * *$
$-.22 * * *$
-.10
-.11
$(0.84)$

$\begin{array}{cccc}-.07 & .13 & .51 * * * & -.04 \\ -.29 * * * & -.41 * * * & -.14 & -.20 * * * \\ -.03 & -.15 * * & .02 & -.27 * * * \\ -.11 & -.10 & .10 & -.16 \\ .07 & .05 & .20 * * * & -.12 \\ .41 * * * & .49 * * * & .18 * * * & .44 * * * \\ (0.69) & .53 * * * & .34 * * * & .25 * * * \\ & (0.69) & .42 * * * & .22 * * * \\ & & (0.88) & .12 \\ & & & (0.72)\end{array}$

$\begin{array}{rrrr}\text { Mean } & 33.74 & 41.33 & 36.78 \\ \text { SD } & 9.00 & 6.22 & 7.16\end{array}$

29.64
8.0

36.67

46.83

27.34

17.66


Table 2: Pattern matrix of non-parametric factor analysis (oblique rotation) for study data (loadings over 0.4 underlined).

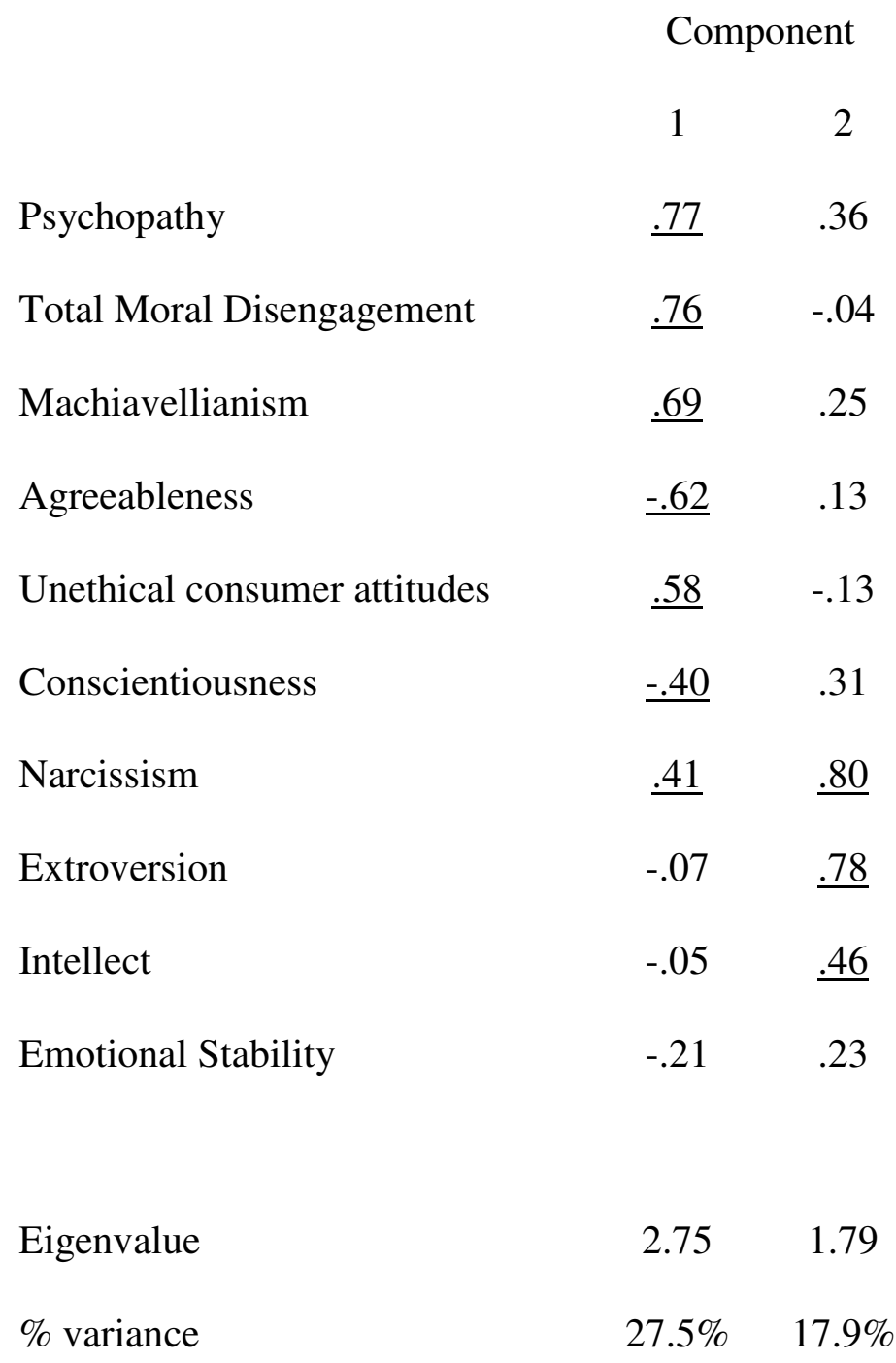

Table legend: components 1 and $2 r=-0.09$. 
Table 3: Multiple regression models of moral disengagement and unethical consumer attitudes with ranked data $(n=380)$.

Outcome: Moral disengagement Overall $\mathrm{F}(11,368)=19.14, \mathrm{P}<.001$

\section{Block}

1. Demographics

2. General personality

3. Dark Triad
Significant Independent predictors (standardised beta, $\mathrm{P}<$ )

Age $(-0.16, \mathrm{P}<.001)$

Education $(0.11, \mathrm{P}<.009)$

Intellect $(-0.14, \mathrm{P}<.002)$

Psychopathy $(0.37, \mathrm{P}<.001)$

Machiavellianism $(0.17, \mathrm{P}<.001)$
Overall Adjusted R2 R2 change Significance of change $\mathrm{R}$

$0.31 \quad 0.09$

$\begin{array}{lll}0.42 & 0.16 & 0.08\end{array}$

.001

0.60

0.35

0.18

.001

Outcome: unethical consumer behaviour $(\mathrm{F}(12,367)=13.55, \mathrm{P}<.001)$.

\section{Block}
1. Demographics
2. General personality
3. Dark Triad
4. Moral disengagement

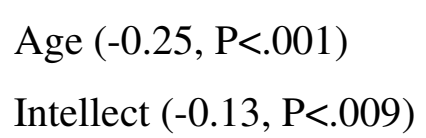

Significant Independent predictors (standardised beta, $\mathrm{P}<$ )
Overall Adjusted R2 R2 change

Significance of change $\mathrm{R}$

$\begin{array}{llll}0.41 & 0.17 & & .001 \\ 0.47 & 0.21 & 0.06 & .001 \\ 0.50 & 0.23 & 0.03 & .003 \\ 0.55 & 0.28 & 0.06 & .001\end{array}$

